\title{
The new dissemination of knowledge: digital libraries and institutional roles in scholarly publishing
}

Mackenzie Owen, John (owen@hum.uva.nl)

Department of Information Science

University of Amsterdam

Oude Turfmarkt 147

NL-1012GC Amsterdam

The Netherlands

\section{Introduction}

During the previous century, knowledge dissemination by means of scholarly publications has developed into a sophisticated communication system in which commercial publishers play an important role. This system is now being transformed by digitisation and the use of the network, i.e. by changes in what nowadays is referred to as the information infrastructure. These changes have led to proposals for new models for scholarly communication itself (e.g. Ginsparg et al. 1999, Harnad 1999, Schulenburger 1998). However, no single actor in the information chain is responsible for the design and quality of the system as a whole, and therefore there is little control over the migration towards new communication models. This is exemplified by numerous policy statements, business models and projects from libraries, academic institutions and publishers.

In this paper we shall argue that one of the main characteristics of the new dissemination of knowledge will be a shift from functionally distributed responsibilities to a more integral responsibility held by the academic community. We shall also look at the consequences this might have for other actors involved in scholarly communication, and argue that these changes will force them to change their focus on information products to a more service-oriented role.

The emphasis in this article is not on economic aspects and theory per se. Rather it serves to describe the context on which a more thorough economic analysis may be based.

\section{The transformation of the information chain}

The traditional model for scholarly communication is usually referred to as the information chain (Mackenzie Owen and Van Halm 1989; Meadows 1991; Duff 1997). This model describes a series of information processes through which recorded knowledge is transmitted from the originator to the user. Each step in the information chain is characterised by three main aspects: role, actor and functions. Roles include knowledge creation, publishing, distribution, archiving, intermediation and use. The key actors that perform these roles include researchers or research institutes, publishers, subscription agents and booksellers, libraries and users. Each of these actors performs specific functions within the context of their respective roles. For instance, the functions of publishers can be defined in a task-oriented way to include selection, certification, editing, printing, marketing and distribution. A more conceptual analysis attributes four 
functions to the publisher: dissemination, quality control, creating a (canonical) archive, and ensuring recognition of authors (Rowland 1997).

What is interesting about the information chain is that it not only defines roles and actors, but that it also identifies the functional responsibilities as perceived and performed by the various actors. This provides an answer to the question raised earlier about the responsibility for the entire process of scholarly communication. There is no overall responsibility held by a single actor, there are only partial responsibilities related to specific roles and functions, and held by specific actors. For instance, the responsibility perceived by academic institutions in most cases extends no farther than creating and documenting knowledge of high scholarly quality. This knowledge, together with the responsibility for carrying out further functions, is then handed over to other actors in the information chain notably publishers. Publishers see it as their responsibility to create information products that meet academic standards and act as a vehicle for wider dissemination of the knowledge they contain. These products are then passed on (via intermediary distributors such as booksellers and subscription agents) to libraries that take on yet other responsibilities, e.g. for archiving, cataloguing \& indexing and delivery of information products to end-users. A key characteristic of the traditional information chain is therefore the distribution of responsibilities over the various actors, based on their respective roles and functions.

The information chain model comes from the world of printed information where knowledge is disseminated by means of 'physical' information products that are manufactured and distributed much like any other tangible product. In the era of print this model has performed extremely well and has developed into a sophisticated co-operative system based on shared interests and mutual understanding of the various actors' interests. It has also adapted itself very well to new technologies at least within the context of print publication and traditional formats such as books and journals. The question now is whether the information chain model will survive in the era of digital information. Information technology has transformed many industries, and has made others obsolete. This begs the question whether the current model of scholarly publishing may be at the end of its life cycle.

There are a number of indicators that suggest this. One is related to the perceived role of publishers. Scholarly knowledge can be regarded as a public good to the extent that it is created through public funding.

Dissemination of knowledge is in the interest of society at large, and is seen by many to transcend purely commercial considerations. That puts publishers in an uncomfortable position within the information chain, surrounded by not-for-profit actors such as scholarly institutions and libraries. However, it has always been widely accepted that for-profit publishing has been beneficial in creating a professional, global dissemination system. Commercial motivations and a responsibility towards the advancement of science were sufficiently balanced. One reason for this would seem to be a 'publishing ethos' grounded in the cultural history of publishing (where scholarly publishers identified themselves more with the academic than with the commercial world) and in the close personal contacts between publishers and academics as suppliers of texts.

Increasingly, however, the publishers' emphasis is shifting from a 
responsibility towards science and scholarship to a contribution to shareholder value, possibly correlated with the increasing scale of the industry and the resulting lack of contacts and identification of managers of publishing firms with the academic community. The commercialisation of scholarly publishing has resulted in unacceptably high costs (an outcome of the so-called 'serials crisis', cf. Cummings 1992, Kaufman 1998, Mobley 1998), restrictive copyright practices and a lack of technical innovation of the dissemination process. There is a growing tension between the opportunities for academics to disseminate knowledge freely over electronic networks and the need of publishers to control access to knowledge for commercial reasons. The partnership - based on shared interests - between academia and commerce is now breaking down, and academic institutions are beginning to perceive the publisher more as an adversary than as a natural partner (cf. the ongoing debate in Nature 2000, Science 2001 and the online responses to Roberts et al. 2001). Such a shift in perception is implicit in many proposals for changes in the scholarly information chain put forward by the academic world (cf. Branin \& Case 1998, Schulenburger 1998, Roberts et al. 2001).

A second indicator - which would appear to result from the perceived publishers' inability to maintain a balance between scholarly and commercial interests - is the extent to which the academic world is beginning to take on the publishing function itself. Examples of 'self publishing' by academics and academic institutions include individual publishing through a personal or institutional website, the use of pre-print servers - also known as 'open archives' (Ginsparg et al. 1999), and the increasing role of academic institutions (e.g. learned societies) which take on a role as non-profit publisher for a specific scientific domain. Individual self-publishing is, of course, highly problematic in terms of quality control and in terms of more general criteria for scholarly publishing, e.g. publicity, trustworthiness and accessibility (Kling and McGim 1999). The issue of quality control through peer review - either in a traditional mode handled by publishers or through alternative mechanisms including electronic peer review over the network - is a subject that continues to create intense discussion (Harnad 1999; Roberts 1999). New solutions are required to avoid a 'review crisis'. Scholarly reviewers often receive little or no rewards, either financially or in recognition, for their review work (although this differs across academic disciplines and some journals do pay substantial fees). They therefore tend to give it low priority. Authors, on the other hand, demand rapid publication and dissemination. The more digitisation and networks make this possible, the more peer review will be perceived as a bottleneck in the communication chain.

Individual self-publishing, open archives and institutional publishing are all examples of a tendency within the academic world to take more overall responsibility for, and control of the scholarly communication chain. This tendency has been expressed by David Schulenburger of the University of Kansas, who has urged the academic community to 'devise a collective agenda to address the effective management of intellectual property to protect and promote scholarly communication' and 'to take responsibility for maintaining or creating low cost venues for print or electronic publication of refereed journals of research finding and scholarly thought' (Schulenburger 1998, cf. Alexander and Goodyear 2000). Researchers from the California Institute of Technology have proposed a new model for scholarly 
communication based on 'a consortium of universities, committed to developing and maintaining an integrated platform supporting all aspects of the scholarly communication process' (Buck, Flagan and Coles 1999).

Statements like these indicate that at least parts of the academic community no longer accept the traditional model based on distributed responsibilities.

The shift of responsibility for scholarly publishing towards academia is but one example of a third indicator of a major transformation of the information chain. This is a mixing of roles and the increasing appropriation of functions by the various actors. Academic institutions, representing authors and users, are taking over functions from the publishers. The same is happening with libraries that are entering the domain of publishing by creating information products such as document repositories and electronic journals (e.g. through the well-known SPARC and CORC initiatives). Publishers have transferred many editing and typesetting functions to the author, sometimes requiring them to produce 'camera-ready copy'. More importantly, they are taking on traditional library functions such as cataloguing \& indexing, short-term archiving, and end-user services such as document delivery.

The only function few actors seem eager to take responsibility for, is longterm archiving. Maintaining accessibility of digital information over a longer period creates problems for which we do not have answers yet. Various solutions have been proposed, including technology museums, migration and emulation (Rothenberg 1999). However, none of these have been tested in practice. The cost per access for older, less frequently used materials could be extremely high if migration costs are taken into account (Mackenzie Owen, 1996). Therefore, if only economic considerations prevail, long-term archiving will certainly be neglected to the point that our intellectual heritage will be lost for future generations. This presents another argument why the academic world may have to accept more responsibility for the information chain as a whole.

\section{The digital library}

A fourth indicator, which suggests a fundamental change in the information chain, is the whole range of initiatives covered by the term 'digital libraries' (DLI-2; Arms 1999; Fox 1999; Chen 2000; for an example of research in this domain, cf. National Science Foundation 2000).

The digital library is not a library in the traditional sense, but an often global organisation of scientists or scholars who use advanced technology to create and share information over the network. This information can be related to research outcomes, but might also consist of source materials, survey data or pre-publication results from ongoing research.

The digital library model is no longer based on the traditional information chain, but on a global infrastructure for knowledge dissemination, a network of researchers who create and distribute knowledge in the form of information objects. These objects increasingly are becoming different from traditional publications such as books and journals; they include text corpora, data collections, audio-visual materials, simulations, embedded software applications, etc. In various digital library projects new document types are being developed, as well as the new technology they require for 
distribution, long-term archiving, navigation, visualisation and retrieval. One example of these new technologies is the concept of multivalent documents (Phelps 1998; Wilensky 2000), which adds useful functionality to document content.

The digital library model is very different from the traditional information chain. It makes no fundamental difference between author, publisher and library functions, and it relates to a far greater richness of information formats and functionalities. In this model, traditional distinctions such as that between monographs and journals are losing importance: the digital library is based on information objects that could have any type of (often dynamic and distributed) formats. In addition, it is based on an integrated approach to the entire information cycle of information creation, distribution and use, and a new, 'human-centered' cyclical model of the scientist's information behaviour (Chien 1997).

\section{The hybrid model of knowledge dissemination}

The technological innovation of libraries has resulted in what can be characterised as a 'hybrid' model of knowledge dissemination. This model combines the two worlds of printed and digital information: some resources are available in digital form over the network, others only in printed form in a library. The hybrid approach reflects the current practice where both printed and digital information are important. However, it is unlikely that this will remain the case. The world of scientific communication is rapidly becoming digital. It is highly probable that within a few years printed publications will play only a very minor role, at least in a number of scholarly domains. And where there is a need for older - i.e. printed publications, they often will be converted to digital form as is already being done in numerous digitisation projects all over the world (e.g. in the wellknown JSTOR project) to improve their distribution and to create more possibilities for archiving, searching, analysing and processing. There is also an increasing emphasis on the use of digital information in academic education, not only within the new 'virtual universities', but also within more traditional settings. Eventually, printed information will become more or less invisible because most users will regard the network as their one and only source of information. This is a practice that already is becoming visible in the information behaviour of many students, and even researchers, and certainly will be true for the future 'net-generation' (Tapscott 1998).

The hybrid form of scientific communication is firmly based on the traditional model of the information chain and on traditional publication forms such as books and journals. However, if we look at the developments described in the previous paragraph, this model seems likely to be only a transitional phase (Rusbridge, 1998) in a development towards fully virtual scientific communication (fig. 1), based on entirely digital, networked information resources and the concept of the 'digital library'. That development would seem to be a logical outcome in a world where scholarly publishers now seem to prefer digital publishing to print (and not exclusively because of cost advantages, cf. King \& Tenopir 1998), where libraries are digitising their most important holdings and offering digital services over the web and where, finally, new generations of academics, for whom the network is the primary source of information, join the research community. 


\section{$<$ Figure 1 here $>$}

The hybrid model is visible in the current organisation of academic libraries, offering both printed resources within the library and digital resources over the network at the user's desktop (Pinfield et al., 1998). It can also be seen in the current practice where scientific publishers produce their journals in both printed and digital form. If our view of future developments is correct, however, then it would seem that the hybrid model as we now know it is approaching the end of its development cycle. This could mean that traditional players in the information chain who are now focussed on consolidating the hybrid model are losing their key positions. That is for instance the conclusion of the European Commission with respect to libraries. The Commission has now ended its Library Programme and put in its place a new programme directed at multimedia information products and technology. In the Digital Libraries Initiative funded by the National Science Foundation in the USA, large portions of the budget (currently in excess of $100 \mathrm{M} \$$ over the two project phases) have been or are being awarded to projects led by a wide range of academic institutions, not just to libraries.

\section{The future of publishing and libraries}

We have argued that the information chain in its current hybrid form based on distributed responsibilities is moving towards a fully digital, virtual mode of scholarly communication for which the overall responsibility will be held by the academic community. What does this mean for publishers? If the academic community takes on full responsibility for and control over the dissemination of knowledge, the role of publishers will certainly change. They no longer will be producers of information products, but will act as service providers to the academic community, performing specific functions for which they are paid rather than for information end-products. The key to this lies in existing functions that can be performed adequately by publishers. An example is quality control through peer review. In any future model, peer review will remain important. But peer review is a function that has to be performed by someone. Publishers have an excellent track record in this area, and there is no reason why they should not be given the opportunity to provide that kind of service, and be paid explicitly for it. The key issue is, however, that publishers will have to perform such functions in an outsourcing relationship under responsibility of the academic community.

The same type of transformation, i.e. from a focus on information products to a service orientation will apply to libraries. Libraries will have to see their future role in the context of a new 'division of order' in the academic world, of which the current digital library initiatives are an early example. They no longer will hold the primary responsibility for scientific information in academic institutions. That responsibility will be anchored at a higher level in these institutions and will involve more actors than just the library. Researchers and research institutions, in their roles as authors and users, will be in far greater control of everything that has to do with information than libraries are used to at the present moment. This will have implications for funding. Researchers will be the primary recipients of funds for information and projects related to information. The library's contribution will be based 
on its information skills, not on its information resources, i.e. a shift from collection to service. The library will have to expand its focus to many other domains of information, including primary digital sources of research information, and support of information work within research projects. Libraries will have to accept that for many types of academic work the information world is an entirely virtual, digital world that integrates many different types of information work and forms, above the custodianship over books and journals. Development of new managerial and technical skills and creation of new alliances with users will be crucial to the library's future role. Also, virtual networked information services tend to be disciplinary ('domain-based'), distributed and international, rather than multidisciplinary, institution-based and local as is the case with most academic libraries.

The transformation towards service-oriented roles therefore implies a fundamental structural change in the organization of scholarly communication (fig. 2).

\section{$<$ Figure 2 here $>$}

\section{Mixed-mode communication}

The transformation of institutional roles towards service functions under control of the academic community is not the only characteristic of the new model of knowledge dissemination that is developing as an outcome of digitisation and networks. The current information chain is mainly based on a single communication mode: the dissemination of research results. The new mode of knowledge dissemination could also include other types of information and serve other information functions. Science and scholarship would benefit from what could be described as mixed-mode communication, based on an integrated information infrastructure that allows the sharing of source data, access to archival materials, networked participation in or at least discussion of ongoing research activities, in addition to access to formal research results. This is precisely what could be the outcome of the developments described in this paper, and especially of what is being developed in the context of digital libraries. For it to happen in a way that really leads to innovation of the dissemination of knowledge and to academic rather than commercial benefits, more overall control of the entire process may be required. The traditional actors in the information chain do not seem capable of achieving this. That would explain why the academic community is now at least discussing the possibility of take on that responsibility.

\section{Knowledge dissemination in the context of application}

So far, we have described knowledge dissemination in terms of the traditional view that scientific knowledge is created and used by researchers working in academic institutions. This is a view that regards the information chain as a closed system, linking producers and consumers of knowledge within the institutionalised world of research. However, there are other domains where knowledge production takes place. Michael Gibbons et al. have described an entirely different domain of knowledge production (Gibbons et al. 1994), which they designate as 'Mode-2' as opposed to the 
traditional mode of academic knowledge production ('Mode-1'). Mode-2 knowledge is created 'in the context of application', i.e. when real-life problems are studied and solved outside universities and research institutes.

This type of knowledge production is carried out in government and business organisation by heterogeneous, interdisciplinary teams. Typically, people from diverse backgrounds (government and public sector organisations, different types of business firms and research institutions) work together in temporary groups for as long as is needed to solve a particular problem. Since this problem-solving is carried out by people with an academic training and using standard research methods and techniques, is leads to knowledge creation in an application context. Mode- 2 reverses the traditional flow from fundamental to applied research. In many cases, solving problems 'in action' leads to fundamental issues that are then passed on to groups carrying out fundamental research in formal research institutions.

Although the views of Gibbons et al. have found wide acceptance, some criticisms can be made. Dominique Pestre has argued that 'mode 2' is not, as Gibbons et al. suggest, a recent category (Pestre 1997). He shows, on the basis of an historical analysis, that already for many centuries two distinct systems of practice have existed in parallel: the 'closed' academic system and an 'open' system where philosophers and scientists work in conjunction with the non-academic world (e.g. the market and the state). More importantly, Richard Whitley has argued that the mode 1 / mode 2 distinction is too radical and that they describe two extremes between which a large variety of research and research organisation can be found (Whitley 2000).

What interests us here, however, is not whether 'mode 2' research is a distinct category. In the context of this paper it is interesting to look at types of research where the characteristics of 'mode 2' are relevant as far as knowledge dissemination is concerned. These are types of knowledge production, usually found outside academic institutions, where the emphasis is on knowledge production 'in action' in a real-life setting rather than in the laboratory, and on internal problem solving and innovation rather than on discovery and the dissemination of knowledge to the outside world. Gibbons et al. argue convincingly that knowledge produced under these circumstances does find wider dissemination outside the initial problem context. This happens through informal networks and through the migration of researchers from one group or problem area to another. This type of dissemination is also highly interdisciplinary (or 'transdisciplinary') due to the heterogeneous composition of the research groups, whereas knowledge transfer in strictly academic research tends to be mono-disciplinary. Gibbons also points out that quality control in non-academic research differs from that in academic research because social, economic and political aspects are taken into account in addition to purely scientific considerations.

Gibbons et al. describe Mode-2 as a 'web' of sites or nodes where research is carried out. Information and communication technologies allow these nodes to interact. The result is a socially distributed knowledge production system where communication increasingly takes place across existing institutional boundaries. Following Whitley, we suggest that many types of research and research disciplines have adopted such ICT-induced web-characteristics, but 
to varying degrees.

Where that is the case, one can also expect to find a number of characteristics of the mixed-mode communication described above.

Research 'in action', involving many organisationally distributed participants linked together through communication networks must almost by nature lead to dissemination and sharing of heterogeneous information, including source and archival data, information on the ongoing research process as well as research outcomes.

An interesting issue for further study is the question whether the development of web-based dissemination and digital libraries will change scientific fields that are based to a high degree on a 'mode 1' type of practice. More specifically, the question can be raised whether these developments could have a unifying effect on the different practices of research as far as knowledge dissemination is concerned, leading to a more open model of digital libraries that will bring together highly formalized and individualized practice of peer-reviewed publishing and the more informal, community-based practice of 'research in action'.

At least two factors can be identified that suggest that such a unifying effect will not in come about at least in the short term. One is the area of quality control, since a 'mode-2' type of research requires, as Gibbons argues, a more composite and multidimensional approach than is offered by the traditional peer review mechanism. The other problematic area is the relationship between authorship and academic status. Even though multiauthorship is becoming more and more common in academic research, authorship remains an important mechanism for providing identity, recognition and status to individual researchers and institutions. In a 'mode2 ' type of practice authorship is less important and, in fact, often cannot be attributed to individuals researchers and institutions.

\section{Summary conclusions}

The ideas developed in this paper can be summarised as follows. Scholarly communication and knowledge dissemination are based on an 'information chain' model that originates from the domain of printed information products. There are a number of indicators that point to a structural change in the traditional system of knowledge dissemination now we are entering the era of digitisation and networks. These indicators include the focus of publishers on shareholder value, the many attempts at self-publishing by the academic world, the loss of functional specialisation in the information chain, and initiatives aimed at developing 'digital libraries' as global networks for creating and distributing knowledge. In the past decade the information chain has developed into a hybrid system, incorporating both printed and digital information and services. This hybrid system is only a transitional phase in the development towards fully digital, networked scholarly communication. A major characteristic of this new system is that the academic world will take responsibility for and gain control over the entire process of communication from knowledge producer to consumer. This will result in a change in institutional roles of and relationships between the actors in the information chain. Publishers and libraries will change from product-oriented organisations to service-oriented organisations, supporting scholarly communication in an outsourcing 
relationship with the academic world. The new system will be based on mixed-mode communication integrating dissemination and sharing of heterogeneous information, including source and archival data, information on the ongoing research process as well as research outcomes. This will be similar to what is already the case in the 'mode-2' type of knowledge production as described by Gibbons et al. However, it remains to be seen whether knowledge dissemination in institutionalised, discipline-based academic research and in non-academic 'research in action' will evolve towards a single system for knowledge dissemination. The main barriers to such integration are created by different conceptions of quality control and authorship in the two modes of research. 


\section{REFERENCES}

Alexander, A.; Goodyear, M. (2000) 'Changing the role of research libraries in scholarly communication', Journal of electronic publishing, 5(3).

(www.press.umich.edu/jep/05-03/alexander.html)

Arms, W.Y. (1999) Digital libraries, Cambridge MA, MIT Press.

Branin, J.J.; Case, M. (1998) 'Reforming Scholarly Publishing in the Sciences: A Librarian Perspective', Notices of the AMS, April 1998. (http://www.ams.org/notices/199804/branin.pdf)

Brophy, P. (1999) Digital library research overview: final report, Centre for Research in Library and Information Management, Department of Information \& Communications, Manchester Metropolitan University. (www.lic.gov.uk/research/digital/review.rtf)

Buck, A.M.; Flagan, R.C.; Coles, B. (1999) Scholars forum: a new model for scholarly communication.

(http://library.caltech.edu/publications/scholarsforum/)

Chen, H., ed. (2000) - Digital libraries. Special topic issue of the Journal of the American Society for Information Science, 51(2000)3/4.

Chien, Y.T. (1997) 'Digital libraries, knowledge networks, and humancentered information systems', in Proceedings of the International Symposium on Research, Development and Practice in Digital Libraries, ISDL'97, Tsukuba, Ibaraki, Japan, November 18-21, 1997. (www.dl.ulis.ac.jp/ISDL97/proceedings/ytchien/ytchien.html)

Cummings, A.M. et al. (1992) University libraries \& scholarly communication: a study prepared for the Andrew W. Mellon Foundation, ARL, November 1992, chapter 6. (www.arl.org/scomm/mellon)

DLI-2 Digital Libraries Initiative, Phase 2. - www.dli2.nsf.gov.

Duff, A.S. (1997) 'Some post-war models of the information chain', Journal of librarianship and information science, 29(4): 179-187.

Fox, E.A., ed. (1999) 'The Digital Libraries Initiative: update and discussion', Bulletin of the American Society for Information Science, Special section, 26(1): 7-27.

Gibbons, M. et al. (1994) The new production of knowledge. - London: Sage Publications, 1994.

Ginsparg, P.; Luce, R.; Sompel, H. van de (1999) The UPS initiative aimed at the further promotion of author self-archived solutions, Los Alamos: Los Alamos National Laboratory. (http://www.openarchives.org/ups-invitationori.htm)

Harnad, S. (1999) Learned enquiry and the net: the role of peer review, peer commentary and copyright.

(http://interarch.york.ac.uk/intarch/antiquity/electronics/harnad.html) 
Kaufman, P. (1998) 'Structure and Crisis: Markets and Market Segmentation in Scholarly Publishing', The Mirage of Continuity: Reconfiguring Academic Information Resources for the 21st Century, ed. Brian L. Hawkins and Patricia Battin, 178-92. Washington, D.C.: CLIR \& AAU.

King, D.W. and Tenopir, C. (1998) Economic cost models of scientific scholarly journals, paper presented to the ICSU Press workshop, Oxford, 31 March to 2 April 1998. (www.bodley.ox.ac.uk/icsu/kingppr.htm)

Kling, R. and McGim, G. (1999) 'Scholarly communication and the continuum of electronic publishing', Journal of the American Society for Information science, 50(10): 890-906.

Mackenzie Owen, J.S.; Halm, J. van (1989) Innovation in the information chain: the effects of technological development on the provision of scientific and technical information, London: Routledge.

Mackenzie Owen, J.S. (1996) 'Preservation of digital materials for libraries', LIBER quarterly, 6(4): 435-451.

Meadows, A.J., ed. (1991) Knowledge and communication: essays on the information chain, London: Library Association Publishing.

Mobley, E.E. (1998) 'Ruminations on the Sci-Tech Serials Crisis', Issues in science and technology librarianship, Fall 1998.

(www.library.ucsb.edu/istl/98-fall/article4.html)

National Science Foundation (2000) National Science, Mathematics, Engineering and Technology Education Digital Library - Program solicitation (NSF 00-44). - Arlington: NSF. (http://www.nsf.gov/cgibin/getpub?nsf0044)

Nature (2000) Future e-access to the primary literature Nature Web-debate. (www.nature.com.nature/debates/e-access/index.html)

Pestre, D. (1997) 'La production des savoirs entre académies et marche: une relecture historique du livre "The new production of knowledge" édité par M. Gibbons', Revue d'Économie industrièlle, 97(0), 1st Trimester 1997: 163-74.

Phelps, Th. A. (1998) 'Multivalent documents: anytime, anywhere, any type, every way user-improvable digital documents and systems', Ph.D. dissertation, University of Berkeley. (www.cs.berkeley.edu/ phelps/papers/dissertation- abstract.html)

Pinfield, S. et al. (1998) 'Realizing the Hybrid Library', D-Lib Magazine, October 1998. (http://www.dlib.org/dlib/october98/10pinfield.html)

Roberts, R.J. (1999) 'Scholarly publishing, peer review and the Internet', First Monday, April 1999. (www.firstmonday.dk/issue4_4/proberts/)

Roberts, R.J. et al. (2001) 'Building a "GenBank" of the published literature', Science, March 23;5512(291):2318-2319. 
Rothenberg (1999) Avoiding technological quicksand: finding a viable foundation for digital preservation. - Council on Library and Information Research. (www.clir.org/pubs/reports/rothenberg/contents.html)

Rowland, F. (1997) 'Print journals: fit for the future?', Ariadne, issue 7, January 1997. (www.ukoln.ac.uk/ariadne/issue7/fytton/)

Rusbridge, Ch. (1998) 'Towards the Hybrid Library', D-Lib Magazine, July/August 1998.

(http://www.dlib.org/dlib/july98/rusbridge/07rusbridge.html)

Science (2001) 'Science's response: is a government archive the best option?', Science, March 23;5512(291):2318.

(www.sciencemag.org/cgi/content/full/291/5512/2318b)

Schulenburger (1998) Scholarly communication and the need for collective action: a statement by the Chief Academic Officers of the Big 12.

(www.big12plus.org/pressreleases/scholar.html)

Tapscott, D. (1998) Growing up digital: the rise of the net generation, New York: McGraw-Hill.

Whitley, R. (2000) The intellectual and social organization of the sciences, $2^{\text {nd }}$ ed., Oxford: Oxford University Press.

Wilensky, R. (2000) 'Digital library resources as a basis for collaborative work', Journal of the American Society for Information Science, 51(3): 228245. 
Figure 1

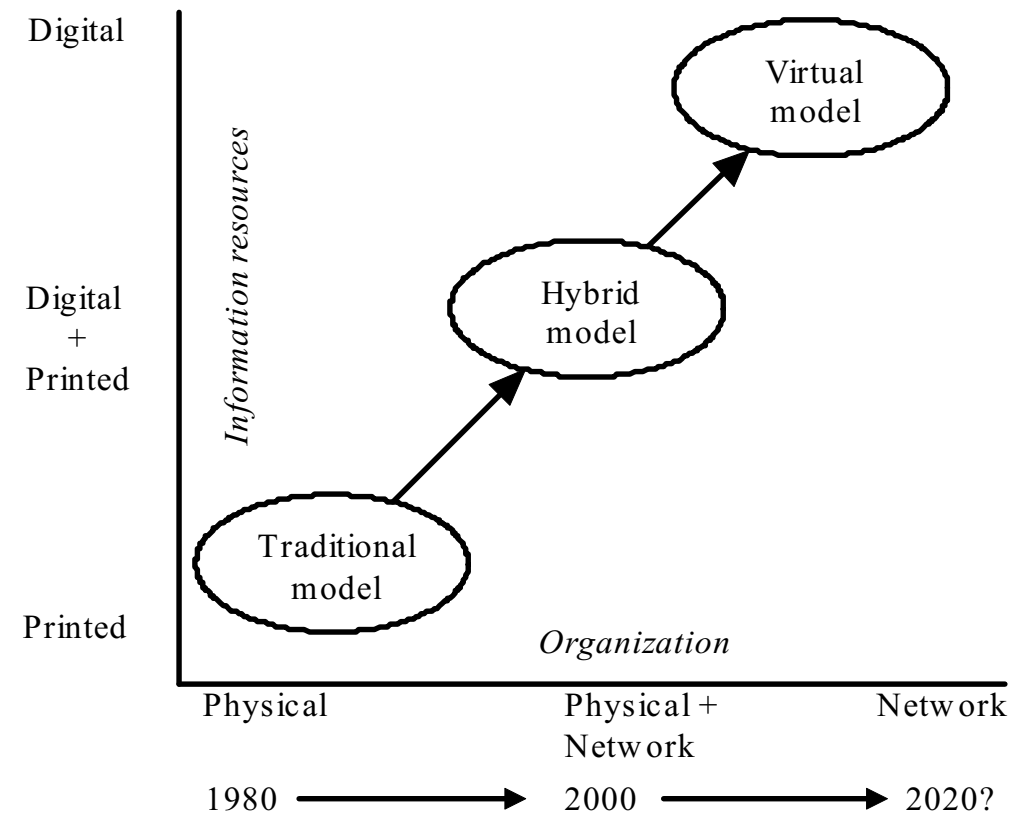


Figure 2

Traditional Information Chain

Author

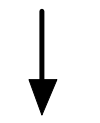

Publisher

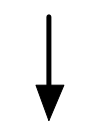

Library

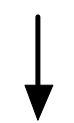

User
New Disseminationof Knowledge

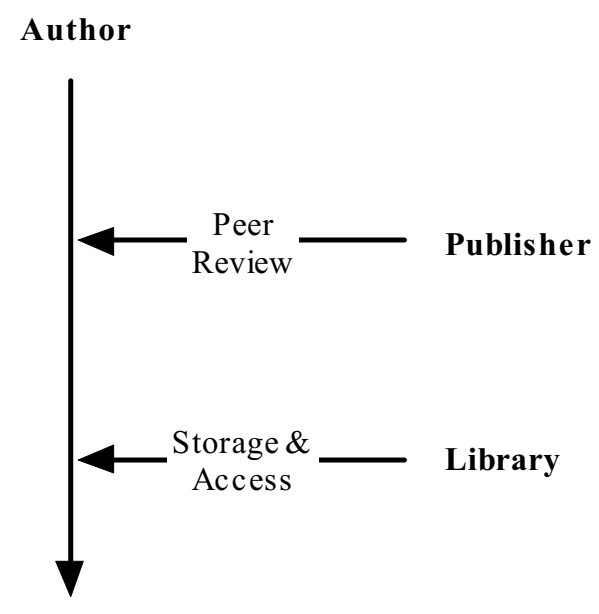

User 